Journal of Mathematics and Statistics 5 (4): 379-386, 2009

ISSN 1549-3644

(C) 2009 Science Publications

\title{
Stochastic Optimization for Portfolio Selection Problem with Mean Absolute Negative Deviation Measure
}

\author{
Anton Abdulbasah Kamil, Adli Mustafa and Khlipah Ibrahim \\ Mathematics Program, School of Distance Education, University Sains Malaysia, \\ 11800, Penang, Malaysia
}

\begin{abstract}
Problem statement: The most important character within optimization problem is the uncertainty of the future returns. Approach: To handle such problems, we utilized probabilistic methods alongside with optimization techniques. We developed single stage and two stage stochastic programming with recourse. The models were developed for risk adverse investors and the objective of the stochastic programming models is to minimize the maximum downside semi deviation. We used the so-called "Here-and-Now" approach where the decision-maker makes decision "now" before observing the actual outcome for the stochastic parameter. Results: We compared the optimal portfolios between the single stage and two stage models with the incorporation of the deviation measure. The models were applied to the optimal selection of stocks listed in Bursa Malaysia and the return of the optimal portfolio was compared between the two stochastic models. Conclusion: The results showed that the two stage model outperforms the single stage model in the optimal and in-sample analysis.
\end{abstract}

Key words: Portfolio optimization, maximum semi deviation measure, downside risk, stochastic linear programming

\section{INTRODUCTION}

Portfolio optimization has been one of the important research fields in financial decision making. The most important character within this optimization problem is the uncertainty of the future returns. To handle such problems, we utilize probabilistic methods alongside with optimization techniques. Stochastic programming is our approach to deal with uncertainty. This approach can deal the management of portfolio risk and the identification of optimal portfolio simultaneously. Stochastic programming models explicitly consider uncertainty in some of the model parameters and provide optimal decisions which are hedged against such uncertainty.

Stochastic programming is a branch of mathematical programming where the parameters are random. The objective of stochastic programming is to find the optimum solution to problems with uncertain data.

In the deterministic framework, a typical mathematical programming problem could be stated as:

$$
\begin{array}{ll}
\min _{x} & f(x) \\
\text { s.t } & g_{i}(x) \leq 0, \quad i=1, \ldots m
\end{array}
$$

where, $\mathrm{x}$ is from $\mathrm{R}^{\mathrm{n}}$ or $\mathrm{Z}^{\mathrm{n}}$. Uncertainty, usually described by a random element $\xi(\omega)$, where $\omega$ is a random outcome from a space $\Omega$, leads to situation where instead of just $f(x)$ and $g_{i}(x)$ one has to deal with $\mathrm{f}(\mathrm{x}, \xi(\omega))$ and $\mathrm{g}_{\mathrm{i}}(\mathrm{x}, \xi(\omega))$. Traditionally, the probability distribution of $\xi$ is assumed to known or can be estimated and is unaffected by the decision vector $\mathrm{x}$. The problem becomes decision making under uncertainty where decision vector $\mathrm{x}$ has to be chosen before the outcome from the distribution of $\xi(\omega)$ can be observed.

Markowitz ${ }^{[11,12]}$ used the concept of risk into the problem and introduced mean-risk approach that identifies risk with the volatility (variance) of the random objective. Since 1952, mean-risk optimization paradigm received extensive development both theoretically and computationally. Konno and Yamazaki $^{[10]}$ proposed mean absolute deviation from the mean as the risk measure to estimate the nonlinear variance-covariance of the stocks in the mean-variance model. It transforms the portfolio selection problem from a quadratic programming into a linear programming problem. At the same time, the popularity of downside risk among investors is growing and meanreturn-downside risk portfolio selection models seem to oppress the familiar mean-variance approach. The reason for the success of the former models is that they separate return fluctuations into downside risk and

Corresponding Author: Anton Abdulbasah Kamil, Mathematics Program, School of Distance Education, University Sains Malaysia, 11800, Penang, Malaysia 


\section{J. Math. \& Stat., 5 (4): 379-386, 2009}

upside potential. This is especially relevant for asymmetrical return distributions, for which meanvariance model punish the upside potential in the same fashion as the downside risk. This led Markowitz ${ }^{[12]}$ to propose downside risk measures such as (downside) semi variance to replace variance as the risk measure. Consequently, one observes growing popularity of downside risk models for portfolio selection ${ }^{[13]}$.

Young $^{[14]}$ introduced another linear programming model which maximize the minimum return or minimize the maximum loss (minimax) over time periods and applied to the stock indices from eight countries, from January 1991 until December 1995. The analysis showed that the model performs similarly with the classical mean-variance model. In addition, Young argues that, when data is log-normally distributed or skewed, the minimax formulation might be more appropriate method, compared to the classical meanvariance formulation, which is optimal for normally distributed data.

Dantzig $^{[8]}$ and independently Beale ${ }^{[3]}$ suggested an approach to stochastic programming and termed as stochastic programming with recourse. Recourse is the ability to take corrective action after a random event has taken place. The main innovation is to amend the problem to allow the decision maker the opportunity to make corrective actions after a random event has taken place. In the first stage a decision maker a here and now decision. In the second stage the decision maker sees a realization of the stochastic elements of the problem but he is allowed to make further decisions to avoid the constraints of the problem becoming infeasible.

Stochastic programming is becoming more popular in finance as computing power increases. There have been numerous applications of Stochastic Programming methodology to real life problems over the last two decades. The applicability of stochastic programs to financial planning problems was first recognized by Crane ${ }^{[7]}$. Worzel et al. ${ }^{[15]}$ and Zenios et al. ${ }^{[17]}$ develop multistage stochastic programs with recourse to address portfolio management problems with fixed-income securities under uncertainty in interest rates. The models integrate stochastic programming model for the selection of portfolios with Monte Carlo simulation models of the term structure of interest rates. Hiller and Eckstein [9](1994), Zenios 16 (1995) and Consiglo and Zenios [6](2001) also apply stochastic programs to fixed-income portfolio management problems. Chang et $a l .^{[5]}$ modeled a portfolio selection problem with transaction costs as a two-stage stochastic programming problem and evaluated the model using historical data obtained from the Taiwan Stock Exchange. Their results show that the model outperforms the market and the MV and MAD model.

In this study we develop single stage and two stage stochastic programming with recourse for portfolio selection problem and the objective is to minimize the maximum downside deviation measure of portfolio returns from the expected return. We use the so-called "Here-and-Now" approach where the decision-maker makes decision "now" before observing the actual outcome for the stochastic parameter. The portfolio optimization problem considered in this study follows the original Markowitz formulation and is based on a single period model of investment. At the beginning of a period, an investor allocates capital among various securities. Assuming that each security is represented by a variable, this is equivalent to assigning a nonnegative weight to each variable. During the investment period, a security generates a random rate of return. The change of capital invested observed at the end of the period is measured by the weighted average of the individual rates of return.

The main objective of this study is to compare the optimal portfolio selected using two different stochastic programming models. We compare the optimal portfolios between the single stage and two stage models with the incorporation of deviation measure. This method is applied to the optimal selection of stocks listed in Bursa Malaysia and the return of the optimal portfolio from the two models is compared.

\section{MATERIALS AND METHODS}

Consider a set of securities $I=\{i: i=1,2, \ldots, n\}$ for an investment. At the end of a certain holding period the assets generate returns, $\tilde{\mathrm{r}}=\left(\tilde{\mathrm{r}}_{1}, \tilde{\mathrm{r}}_{2}, \ldots, \tilde{\mathrm{r}}_{\mathrm{n}}\right)^{\mathrm{T}}$. The returns are unknown at the beginning of the holding period, that is, at the time of the portfolio selection and are treated as random variables. Denote their mean value by, $\overline{\mathrm{r}}=\mathrm{E}(\tilde{\mathrm{r}})=\left(\overline{\mathrm{r}}_{1}, \overline{\mathrm{r}}_{2}, \ldots, \overline{\mathrm{r}}_{\mathrm{n}}\right)^{\mathrm{T}}$. At the beginning of the holding period the investor wishes to apportion his budget to these assets by deciding on a specific allocation $\mathrm{x}=\left(\mathrm{x}_{1}, \mathrm{x}_{2}, \ldots, \mathrm{x}_{\mathrm{n}}\right)^{\mathrm{T}}$ such that $\mathrm{x}_{\mathrm{i}} \geq 0$ (i.e., short sales are not allowed) and $\sum_{i \in \mathrm{I}} \mathrm{x}_{\mathrm{i}}=1$ (budget constraint). We use boldface character to denote vectors and $\sim$ to denote random variables.

The uncertain return of the portfolio at the end of the holding period is $\tilde{R}=R(x, \tilde{r})=x^{T} \tilde{r}$. This is a random variable with a distribution function, say $\mathrm{F}$, that is:

$$
\mathrm{F}(\mathrm{x}, \mu)=\mathrm{P}\{\mathrm{R}(\mathrm{x}, \tilde{\mathrm{r}}) \leq \mu\}
$$


We assume that the distribution function $\mathrm{F}$ does not depend on the portfolio composition $\mathrm{x}$. The expected return of the portfolio is:

$$
\overline{\mathrm{R}}=\mathrm{E}[\tilde{\mathrm{R}}]=\mathrm{E}[\mathrm{R}(\mathrm{x}, \tilde{\mathrm{r}})]=\overline{\mathrm{R}}(\mathrm{x}, \tilde{\mathrm{r}})
$$

Suppose the uncertain returns of the assets, $\tilde{\mathrm{r}}$, are represented by a finite set of discrete scenarios $\Omega=\{\omega$ : $\omega=1,2, \ldots, \mathrm{S}$, whereby the returns under a particular scenario $\omega \in \Omega$ take the values $r \omega=\left(r_{1 \omega}, r_{2 \omega} \ldots, r_{n \omega}\right)^{T}$ with associated probability $\mathrm{p}_{\omega}>0, \sum_{\omega \in \Omega} \mathrm{p}_{\omega}=1$. The mean return of the assets is $\overline{\mathrm{r}}=\sum_{\omega \in \Omega} \mathrm{p}_{\omega} \mathrm{r}_{\omega}$. The portfolio return under a particular realization of asset return $r_{\omega}$ is denoted by $\mathrm{R}_{\omega}=\mathrm{R}\left(\mathrm{x}, \mathrm{r}_{\omega}\right)$. The expected portfolio return is expressed as:

$$
\overline{\mathrm{R}}=\overline{\mathrm{R}}\left(\mathrm{x}, \mathrm{r}_{\omega}\right)=\mathrm{E}\left[\mathrm{R}\left(\mathrm{x}, \mathrm{r}_{\omega}\right)\right]=\sum_{\omega \in \Omega} \mathrm{p}_{\omega} \mathrm{R}\left(\mathrm{x}, \mathrm{r}_{\omega}\right)
$$

Let $\mathrm{M}\left[\mathrm{R}\left(\mathrm{x}, \mathrm{r}_{\omega}\right)\right]$ be the minimum of the portfolio return. The maximum (downside) semideviation measure is defined as:

$$
\kappa(x)=\operatorname{MM}\left[R\left(x, r_{\omega}\right)\right]=\left[E\left[R\left(x, r_{\omega}\right)\right]-\operatorname{Min}\left[R\left(x, r_{\omega}\right)\right]\right.
$$

Maximum downside deviation risk $\operatorname{MM}\left[\mathrm{R}\left(\mathrm{x}, \mathrm{r}_{\omega}\right)\right]$ is a very pessimistic risk measure related to the worst case analysis. It does not take into account the distribution of outcomes other than the worst one.

Properties of the $\operatorname{MM}[\mathbf{R}(\mathbf{x}, \tilde{\mathbf{r}})]$ measures: Since being introduces in ${ }^{[2]}$, the axiomatic approach to construction of risk measures has been repeatedly employed by many authors for development of other types of risk measures, tailored to specific preferences and applications $^{[1,13]}$.

Proposition 1: $\operatorname{MM}[\mathrm{R}(\mathrm{x}, \tilde{\mathrm{r}})]$ measure is a deviation measure.

\section{Proof:}

- Subadditivity: $\kappa\left(\mathrm{X}_{1}+\mathrm{X}_{2}\right) \leq \kappa\left(\mathrm{X}_{1}\right)+\kappa\left(\mathrm{X}_{2}\right)$ :

$$
\begin{aligned}
& \operatorname{MM}\left[\mathrm{R}_{1}(\mathrm{x}, \tilde{\mathrm{r}})+\mathrm{R}_{2}(\mathrm{x}, \tilde{\mathrm{r}})\right] \\
&= \max \left\{\mathrm{E}\left[\mathrm{R}_{1}(\mathrm{x}, \tilde{\mathrm{r}})+\mathrm{R}_{2}(\mathrm{x}, \tilde{\mathrm{r}})\right]\right. \\
&\left.-\left[\mathrm{R}_{1}(\mathrm{x}, \tilde{\mathrm{r}})+\mathrm{R}_{2}(\mathrm{x}, \tilde{\mathrm{r}})\right]\right\} \\
&= \max \left\{\left(\mathrm{E}\left[\mathrm{R}_{1}(\mathrm{x}, \tilde{\mathrm{r}})\right]-\mathrm{R}_{1}(\mathrm{x}, \tilde{\mathrm{r}})\right)\right. \\
&+\left(\mathrm{E}\left[\mathrm{R}_{2}(\mathrm{x}, \tilde{\mathrm{r}})\right]-\mathrm{R}_{2}(\mathrm{x}, \tilde{\mathrm{r}})\right\} \\
& \leq \max \left\{\mathrm{E}\left[\mathrm{R}_{1}(\mathrm{x}, \tilde{\mathrm{r}})\right]-\mathrm{R}_{1}(\mathrm{x}, \tilde{\mathrm{r}})\right\} \\
&+\max \left\{\mathrm{E}\left[\mathrm{R}_{2}(\mathrm{x}, \tilde{\mathrm{r}})\right]-\mathrm{R}_{2}(\mathrm{x}, \tilde{\mathrm{r}})\right\} \\
& \leq \operatorname{MM}\left[\mathrm{R}_{1}(\mathrm{x}, \tilde{\mathrm{r}})\right]+\operatorname{MM}\left[\mathrm{R}_{2}(\mathrm{x}, \tilde{\mathrm{r}})\right]
\end{aligned}
$$

- Positive homogeneity:

$$
\begin{aligned}
& \operatorname{MM}[0]=\max (E[0]-0)=0 \\
& \begin{aligned}
\operatorname{MM}[\lambda(\mathrm{R}(\mathrm{x}, \tilde{\mathrm{r}})] & =\max \{\mathrm{E}[\lambda \mathrm{R}(\mathrm{x}, \tilde{\mathrm{r}})]-\lambda \mathrm{R}(\mathrm{x}, \tilde{\mathrm{r}})\} \\
& =\lambda \max \{\mathrm{E}[\mathrm{R}(\mathrm{x}, \tilde{\mathrm{r}})]-\mathrm{R}(\mathrm{x}, \tilde{\mathrm{r}})\} \\
& =\lambda \operatorname{MM}[\mathrm{R}(\mathrm{x}, \tilde{\mathrm{r}})], \text { for all } \lambda>0
\end{aligned}
\end{aligned}
$$

- Translation invariance: $\kappa(X+\alpha)=\kappa(X)-\alpha$, for all real constant $\alpha$ :

$$
\begin{aligned}
\operatorname{MM}[(\mathrm{R}(\mathrm{x}, \tilde{\mathrm{r}})+\alpha] & =\max \{\mathrm{E}([\mathrm{R}(\mathrm{x}, \tilde{\mathrm{r}})+\alpha]-[\mathrm{R}(\mathrm{x}, \tilde{\mathrm{r}})+\alpha])\} \\
& =\max \{\mathrm{E}[\mathrm{R}(\mathrm{x}, \tilde{\mathrm{r}})]+\alpha-\mathrm{R}(\mathrm{x}, \tilde{\mathrm{r}})-\alpha\} \\
& =\max \{\mathrm{E}[\mathrm{R}(\mathrm{x}, \tilde{\mathrm{r}})]-\mathrm{R}(\mathrm{x}, \tilde{\mathrm{r}})\} \\
& =\operatorname{MM}[(\mathrm{R}(\mathrm{x}, \tilde{\mathrm{r}})]
\end{aligned}
$$

- Convexity: $\kappa\left[\lambda \mathrm{X}_{1}+(1-\lambda) \mathrm{X}_{2}\right] \leq \lambda \kappa\left(\mathrm{X}_{1}\right)+(1-\lambda) \kappa\left(\mathrm{X}_{2}\right)$ for all $\lambda \in[0,1]$ :

$$
\begin{aligned}
\mathrm{MM}[ & \left.\lambda \mathrm{R}_{1}(\mathrm{x}, \tilde{\mathrm{r}})+(1-\lambda) \mathrm{R}_{2}(\mathrm{x}, \tilde{\mathrm{r}})\right] \\
= & \max \left\{\mathrm{E}\left[\lambda \mathrm{R}_{1}(\mathrm{x}, \tilde{\mathrm{r}})+(1-\lambda) \mathrm{R}_{2}(\mathrm{x}, \tilde{\mathrm{r}})\right]\right. \\
& \left.-\left[\lambda \mathrm{R}_{1}(\mathrm{x}, \tilde{\mathrm{r}})+(1-\lambda) \mathrm{R}_{2}(\mathrm{x}, \tilde{\mathrm{r}})\right]\right\} \\
= & \max \left\{\left(\mathrm{E}\left[\lambda \mathrm{R}_{1}(\mathrm{x}, \tilde{\mathrm{r}})\right]+\mathrm{E}\left[(1-\lambda) \mathrm{R}_{2}(\mathrm{x}, \tilde{\mathrm{r}})\right)\right]\right. \\
& \left.-\lambda \mathrm{R}_{1}(\mathrm{x}, \tilde{\mathrm{r}})+(1-\lambda) \mathrm{R}_{2}(\mathrm{x}, \tilde{\mathrm{r}})\right\} \\
= & \max \left\{\lambda\left(\mathrm{E}\left[\mathrm{R}_{1}(\mathrm{x}, \tilde{\mathrm{r}})\right]-\mathrm{R}_{1}(\mathrm{x}, \tilde{\mathrm{r}})\right)\right. \\
& \left.+(1-\lambda)\left(\mathrm{E}\left[\mathrm{R}_{2}(\mathrm{x}, \tilde{\mathrm{r}})\right]-\mathrm{R}_{2}(\mathrm{x}, \tilde{\mathrm{r}})\right)\right\} \\
\leq & \lambda \max \left\{\left(\mathrm{E}\left[\mathrm{R}_{1}(\mathrm{x}, \tilde{\mathrm{r}})\right]-\mathrm{R}_{1}(\mathrm{x}, \tilde{\mathrm{r}})\right)\right\} \\
& \left.+(1-\lambda) \max \left\{\mathrm{E}\left[\mathrm{R}_{2}(\mathrm{x}, \tilde{\mathrm{r}})\right]-\mathrm{R}_{2}(\mathrm{x}, \tilde{\mathrm{r}})\right)\right\} \\
\leq & \lambda \operatorname{MM}\left[\mathrm{R}_{1}(\mathrm{x}, \tilde{\mathrm{r}})\right]+(1-\lambda) M M\left[\mathrm{R}_{2}(\mathrm{x}, \tilde{\mathrm{r}})\right]
\end{aligned}
$$

Single stage stochastic programming portfolio optimization model with MM deviation measure: We formulate the portfolio selection optimization model as a single stage stochastic programming model as follows:

Definition 1: S_MM: The stochastic portfolio optimization problem where the difference between the expected portfolio return and the maximum of minimum portfolio returns is minimized and constraining the expected portfolio return is:

$\underset{\mathrm{x} \in \mathrm{X}}{\operatorname{Minimize}} \max _{\omega \in \Omega}\left[\overline{\mathrm{R}}\left(\mathrm{x}, \mathrm{r}_{\omega}\right)-\mathrm{R}\left(\mathrm{x}, \mathrm{r}_{\omega}\right)\right]$

Subject to:

$\mathrm{R}\left(\mathrm{x}, \mathrm{r}_{\omega}\right)=\sum_{\mathrm{i} \in \mathrm{I}} \mathrm{x}_{\mathrm{i}} \mathrm{r}_{\omega \mathrm{i}} \quad \forall \omega \in \Omega$ 


$$
\begin{aligned}
& \overline{\mathrm{R}}\left(\mathrm{x}, \mathrm{r}_{\omega}\right)=\sum_{\omega \in \Omega} \mathrm{p}_{\omega} \mathrm{R}\left(\mathrm{x}, \mathrm{r}_{\omega}\right) \\
& \overline{\mathrm{R}}\left(\mathrm{x}, \mathrm{r}_{\omega}\right) \geq \alpha \\
& \sum_{\mathrm{i} \in \mathrm{I}} \mathrm{x}_{\mathrm{i}}=1 \\
& \mathrm{~L}_{\mathrm{i}} \leq \mathrm{x}_{\mathrm{i}} \leq \mathrm{U}_{\mathrm{i}}
\end{aligned}
$$

Model S_MM minimizes the maximum semi deviation of portfolio returns from the expected portfolio return at the end of the investment horizon. Equation 4 defines the total portfolio return under each scenario $\omega$. Equation 5 defines the expected return of the portfolio at the end of the horizon, while Eq. 6 constraints the expected return by the target return $\alpha$. Equation 7 insures that the total weights of all investments sum to one, that is, budget constraints ensuring full investment of available budget. Finally Eq. 8 insures that the weights on assets purchased are nonnegative, disallowing short sales and place upper bound on the weights.

Solving the parametric programs (3) for different values of the expected portfolio return $\alpha$ yields the MM-efficient frontier.

Linear programming formulation for S_MM: Models S_MM have a non linear objective function and a set of linear constraints. Thus the models are non linear stochastic programming. However the models can be transformed to linear model as discussed below. let:

For every scenario $\omega \in \Omega$, let an auxiliary variable,

$$
\eta=\max _{\omega \in \Omega}\left[\overline{\mathrm{R}}\left(\mathrm{x}, \mathrm{r}_{\omega}\right)-\mathrm{R}\left(\mathrm{x}, \mathrm{r}_{\omega}\right)\right]
$$

Subject to:

$$
\eta \geq \max _{\omega \in \Omega}\left[\overline{\mathrm{R}}\left(\mathrm{x}, \mathrm{r}_{\omega}\right)-\mathrm{R}\left(\mathrm{x}, \mathrm{r}_{\omega}\right)\right] \text { for } \forall \omega \in \Omega
$$

Then, we have:

$$
\operatorname{MM}\left[R\left(x, r_{\omega}\right)\right]=\eta
$$

Subject to:

$$
\eta \geq \max _{\omega \in \Omega}\left[\overline{\mathrm{R}}\left(\mathrm{x}, \mathrm{r}_{\omega}\right)-\mathrm{R}\left(\mathrm{x}, \mathrm{r}_{\omega}\right)\right] \text { for } \forall \omega \in \Omega
$$

Substituting (10) in portfolio optimization models (3) resulting in the following stochastic linear programming model:
Minimize $\eta$

Subject to:

$$
\begin{aligned}
& R\left(x, r_{\omega}\right)=\sum_{i \in I} x_{i} r_{\omega i} \\
& \bar{R}\left(x, r_{\omega}\right)=\sum_{\omega \in \Omega} p_{\omega} R\left(x, r_{\omega}\right) \\
& \bar{R}\left(x, r_{\omega}\right) \geq \alpha \\
& \bar{R}\left(x, r_{\omega}\right)-R\left(x, r_{\omega}\right) \leq \eta \\
& \sum_{i \in I} x_{i}=1
\end{aligned}
$$

$\mathrm{L}_{\mathrm{i}} \leq \mathrm{x}_{\mathrm{i}} \leq \mathrm{U}_{\mathrm{i}} \quad \forall \mathrm{i} \in \mathrm{I}$

Theorem 1: If $x^{*}$ is an optimal solution to (3), then $\left(x^{*}, \eta^{*}\right)$ is an optimal solution to (11), where $\eta=\max _{\omega \in \Omega}\left[\bar{R}\left(x, r_{\omega}\right)-R\left(x, r_{\omega}\right)\right]$. On the other hand, if $\left(x^{*}, \eta^{*}\right)$ where $\eta=\max _{\omega \in \Omega}\left[\bar{R}\left(x, r_{\omega}\right)-R\left(x, r_{\omega}\right)\right]$ is an optimal solution to (11), then $x^{*}$ is an optimal solution to (3).

Proof: If $x^{*}$ is an optimal solution to (3), then $\left(x^{*}, \eta^{*}\right)$ is a feasible solution to (11), where $\eta=\max _{\omega \in \Omega}\left[\overline{\mathrm{R}}\left(\mathrm{x}^{*}, \mathrm{r}_{\omega}\right)-\mathrm{R}\left(\mathrm{x}^{*}, \mathrm{r}_{\omega}\right)\right]$. If $\left(\mathrm{x}^{*}, \eta^{*}\right)$ is not an optimal solution to (11), then there exists a feasible solution $\quad(x, \eta), \quad$ to $\quad(11)$ where $\eta=\max _{\omega \in \Omega}\left[\bar{R}\left(x, r_{\omega}\right)-R\left(x, r_{\omega}\right)\right]$ such that $\eta \leq \eta^{*}$.

Noticing that $\max _{\omega \in \Omega}\left[\overline{\mathrm{R}}\left(\mathrm{x}, \mathrm{r}_{\omega}\right)-\mathrm{R}\left(\mathrm{x}, \mathrm{r}_{\omega}\right)\right] \leq \eta$, then we have:

$$
\begin{aligned}
\max _{\omega \in \Omega}\left[\overline{\mathrm{R}}\left(\mathrm{x}, \mathrm{r}_{\omega}\right)-\mathrm{R}\left(\mathrm{x}, \mathrm{r}_{\omega}\right)\right] \leq \eta & <\eta^{*} \\
& <\max _{\omega \in \Omega}\left[\overline{\mathrm{R}}\left(\mathrm{x}^{*}, \mathrm{r}_{\omega}\right)-\mathrm{R}\left(\mathrm{x}^{*}, \mathrm{r}_{\omega}\right)\right]
\end{aligned}
$$

which contradicts that $x^{*}$ is an optimal solution to (3).

On the other hand, if $\left(x^{*}, \eta^{*}\right)$ is an optimal solution to (11), where $\eta=\max _{\omega \in \Omega}\left[\bar{R}\left(x, r_{\omega}\right)-R\left(x, r_{\omega}\right)\right]$ then $x^{*}$ is an optimal solution to (3). Otherwise, there exists a feasible solution $\mathrm{x}$ to (3), such that:

$$
\max _{\omega \in \Omega}\left[\overline{\mathrm{R}}\left(\mathrm{x}, \mathrm{r}_{\omega}\right)-\mathrm{R}\left(\mathrm{x}, \mathrm{r}_{\omega}\right)\right]<\max _{\omega \in \Omega}\left[\overline{\mathrm{R}}\left(\mathrm{x}^{*}, \mathrm{r}_{\omega}\right)-\mathrm{R}\left(\mathrm{x}^{*}, \mathrm{r}_{\omega}\right)\right]
$$

Denote by: 


$$
\eta=\max _{\omega \in \Omega}\left[\bar{R}\left(\mathrm{x}, \mathrm{r}_{\omega}\right)-\mathrm{R}\left(\mathrm{x}, \mathrm{r}_{\omega}\right)\right]
$$

then we have:

$$
\begin{aligned}
\eta= & \max _{\omega \in \Omega}\left[\overline{\mathrm{R}}\left(\mathrm{x}, \mathrm{r}_{\omega}\right)-\mathrm{R}\left(\mathrm{x}, \mathrm{r}_{\omega}\right)\right] \\
& <\max _{\omega \in \Omega}\left[\overline{\mathrm{R}}\left(\mathrm{x}^{*}, \mathrm{r}_{\omega}\right)-\mathrm{R}\left(\mathrm{x}^{*}, \mathrm{r}_{\omega}\right)\right] \\
& <\eta^{*}
\end{aligned}
$$

which contradicts that $\left(x^{*}, \eta^{*}\right)$ is an optimal solution to (11).

Two stage stochastic programming model with recourse: We now introduce dynamic model where not only the uncertainty of the returns is included in the model but future changes, recourse, to the initial compositions are allowed. We formulate the portfolio optimization by assuming the investor can make corrective action after the realization of random values by changing the composition of the optimal portfolio. This can be done by formulating the single period stochastic linear programming models with the mean absolute negative deviation measure as a two-stage stochastic programming problem with recourse. The two-stage stochastic programming problem allows a recourse decision made after uncertainty of the returns is realized.

Now, consider the case when the investor is interested in a first stage decision $\mathrm{x}$ that hedges against the risk of the second-stage action. At the beginning of the investment period, the investor selects the initial composition of the portfolio, $\mathrm{x}$. The first stage decision, $\mathrm{x}$ is made when there is a known distribution of future returns. At the end of the planning horizon, once a particular scenario of return is realized, the investor rebalances the composition by either purchasing or selling the selected stocks. In addition to the initial, or first stage, decision variables $\mathrm{x}$, let a set of second stage variables, $\mathrm{y}_{\mathrm{i}, \omega}$ to represent the composition of stock $\mathrm{i}$ after rebalancing is done, i.e., $\mathrm{y}_{\mathrm{i}, \omega}=\mathrm{x}_{\mathrm{i}}+\mathrm{P}_{\mathrm{i}, \omega}$ or $\mathrm{y}_{\mathrm{i}, \omega}=\mathrm{x}_{\mathrm{i}}{ }^{-}$ $\mathrm{Q}_{\mathrm{i}, \omega}$ where $\mathrm{P}_{\mathrm{i}, \omega}$ and $\mathrm{Q}_{\mathrm{i}, \omega}$ are the quantity purchased and sold respectively. $\mathrm{y}_{\mathrm{i}, \omega}$ is selected after the uncertainty of returns is realized.

Linear representation of MM: Before formulating the two stage stochastic programming models for portfolio optimization problem to minimize the second stage risk measure, let formulate mean absolute negative deviation and maximum downside deviation of portfolio returns from the expected return in terms of the second stage variables $y$ :

$$
\text { Let } \begin{aligned}
\kappa\left(\mathrm{R}\left(\mathrm{y}_{\omega}, \mathrm{r}_{\omega}\right)\right) & =\operatorname{MM}\left[\mathrm{R}\left(\mathrm{y}_{\omega}, \mathrm{r}_{\omega}\right)\right] \\
& =\max _{\omega \in \Xi}\left[\overline{\mathrm{R}}\left(\mathrm{y}_{\omega}, \mathrm{r}_{\omega}\right)-\mathrm{R}\left(\mathrm{y}_{\omega}, \mathrm{r}_{\omega}\right)\right]
\end{aligned}
$$

For every scenario $\omega \in \Omega$, let the auxiliary variable:

$$
\eta=\max _{\omega \in \Omega}\left[\overline{\mathrm{R}}\left(\mathrm{y}_{\omega}, \mathrm{r}_{, \omega}\right)-\mathrm{R}\left(\mathrm{y}_{\omega}, \mathrm{r}_{\omega}\right)\right]
$$

\section{Subject to:}

$\eta \geq \max _{\omega \in \Omega}\left[\overline{\mathrm{R}}\left(\mathrm{y}_{\omega}, \mathrm{r}_{\omega}\right)-\mathrm{R}\left(\mathrm{y}_{\omega}, \mathrm{r}_{\omega}\right)\right]$ for $\forall \omega \in \Omega$

Then, we have:

$\operatorname{MM}\left[R\left(x, r_{\omega}\right)\right]=\eta$

Subject to:

$$
\eta \geq \max _{\omega \in \Omega}\left[\overline{\mathrm{R}}\left(\mathrm{y}_{\omega}, \mathrm{r}_{\omega}\right)-\mathrm{R}\left(\mathrm{y}_{\omega}, \mathrm{r}_{\omega}\right)\right] \text { for } \forall \omega \in \Omega
$$

Two stage stochastic linear programming formulation of 2S_MM: We formulate the two stage stochastic linear programming model for portfolio optimization problem that hedge against second stage $\mathrm{MM}$ as follows:

Definition 2: 2S_MM: The stochastic portfolio optimization problem where the downside maximum semideviation of portfolio returns from the expected return is minimized and constraining the expected portfolio return is:

Minimize $\eta$

Subject to:

$\sum_{\mathrm{i} \in \mathrm{I}} \mathrm{x}_{\mathrm{i}}=1$

$\sum_{\mathrm{i} \in \mathrm{I}} \mathrm{y}_{\omega \mathrm{i}}=1$

$\forall \omega \in \Omega$

$\overline{\mathrm{R}}\left(\mathrm{x}, \mathrm{r}_{\omega}\right)+\mathrm{R}\left(\mathrm{y}_{\omega}, \mathrm{r}_{\omega}\right) \geq \alpha \quad \forall \omega \in \Omega$

$\mathrm{L}_{\mathrm{i}} \leq \mathrm{x}_{\mathrm{i}} \leq \mathrm{U}_{\mathrm{i}}$

$\forall i \in I$

$\mathrm{L}_{\omega \mathrm{i}} \leq \mathrm{y}_{\omega \mathrm{\omega i}} \leq \mathrm{U}_{\omega \mathrm{i}} \quad \forall \mathrm{i} \in \mathrm{I}, \forall \omega \in \Omega$

$\mathrm{R}\left(\mathrm{y}_{\omega}, \mathrm{r}_{\omega}\right) \geq \eta \quad \forall \omega \in \Omega$ 
Model (22) minimizes the maximum downside semi deviation of portfolio return from the expected portfolio return of the second stage variables, $y$, at the end of the investment period. Equation 23 insures that the total weights of all investments in the first stage sum to one and Eq. 24 insures that the total weights of all investments in the second stage under each scenario $\omega$ sum to one that is, budget constraints ensuring full investment of available budget. Equation 25 constraints the expected return by the target return, $\alpha$, while Eq. 26 and 27 insures that the weights on assets purchased are nonnegative, disallowing short sales and place upper bound on the weights in the first stage and second stage respectively. Finally Eq. 28 define the mean absolute negative deviation of portfolio returns from the expected portfolio return in the second stage and the auxiliary variables for the linear representation of the deviation measure.

\section{RESULTS}

We tested our models on ten common stocks listed on the main board of Bursa Malaysia. These we tested our models on ten common stocks listed on the main board of Bursa Malaysia. These stocks were selected at random from a set of stocks that were already listed on December 1989 and still in the list on May 2004. The closing prices were obtained from Investors Digest. At the beginning, sixty companies were selected at random. Then, ten stocks were selected and the criterion we use to select the ten stocks in our analysis is described as follows:

- Those companies which do not have complete closing monthly price during the analysis period are excluded

- Since the portfolios are examined on the basis of historical data, those with negative average returns over the analysis period are excluded

We use empirical distributions computed from past returns as equiprobable scenarios. Observations of returns over $\mathrm{N}_{\mathrm{S}}$ overlapping periods of length $\Delta \mathrm{t}$ are considered as the $\mathrm{N}_{\mathrm{S}}$ possible outcomes (or scenarios) of the future returns and a probability of $\frac{1}{N_{\mathrm{s}}}$ is assigned to each of them. Assume that we have $\mathrm{T}$ historical prices, $\mathrm{P}_{\mathrm{t}}, \mathrm{t}=1,2, \ldots, \mathrm{T}$ of the stocks under consideration. For each point of time, we compute the realized return vector over the previous period of 1 month, which will be further be considered as one of the $\mathrm{N}_{\mathrm{S}}$ scenarios for the future returns on the assets. Thus, for example, a scenario $r_{\text {is }}$ for the return on asset $\mathrm{i}$ is obtained as:

$\mathrm{r}_{\mathrm{is}}=\frac{\mathrm{P}_{\mathrm{i}}(\mathrm{t}+1)-\mathrm{P}_{\mathrm{i}}(\mathrm{t})}{\mathrm{P}_{\mathrm{i}}(\mathrm{t})}$

For each stock, we obtain 100 scenarios of the overlapping periods of length 1 month, i.e., $\mathrm{N}_{\mathrm{S}}$.

To evaluate the performance of the two models, we examined the portfolio returns resulting from applying the two stochastic optimization models. We make comparison between S_MM and 2S_MM models by analyzing the optimal portfolio returns in-sample portfolio returns and out-of-sample portfolio returns over 60 month period from to $06 / 1998$ to $05 / 2004$. At each month, we use the historical data from the previous 100 monthly observations as scenarios and solve the resulting optimization models and record the return of the optimal portfolio. Then we calculate the in-sample realized portfolio return. The clock is advanced one month and the out-of-sample realized return of the portfolio is determined from the actual return of the assets. The same procedure is then repeated for the next period and the average returns were computed for in-sample and out-of-sample realized portfolio return. We use the minimum monthly required return $\alpha$ equals to one in the analysis for both the S_MM and 2S_MM models.

Comparison of optimal portfolio returns between S_MM and 2S_MM: Figure 1 presents the graphs of optimal portfolio returns resulting from solving the two models; S_MM and 2S_MM.

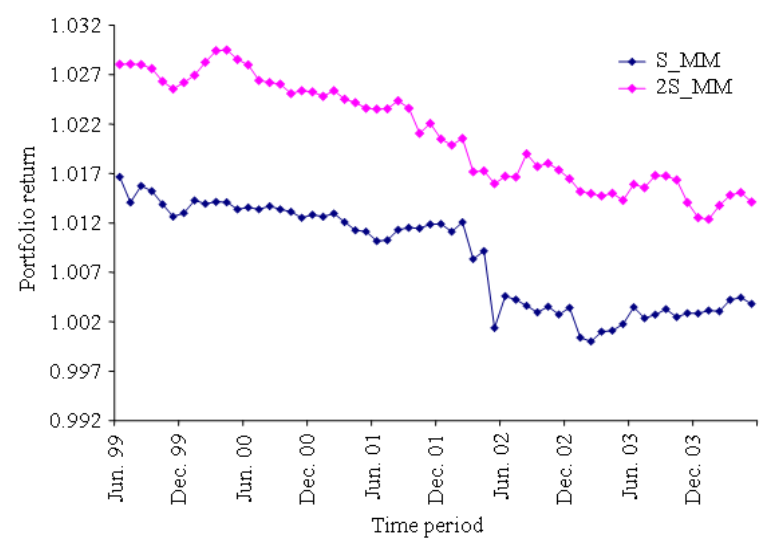

Fig. 1: Comparison of optimal portfolio returns S_MM and 2S_MM models 


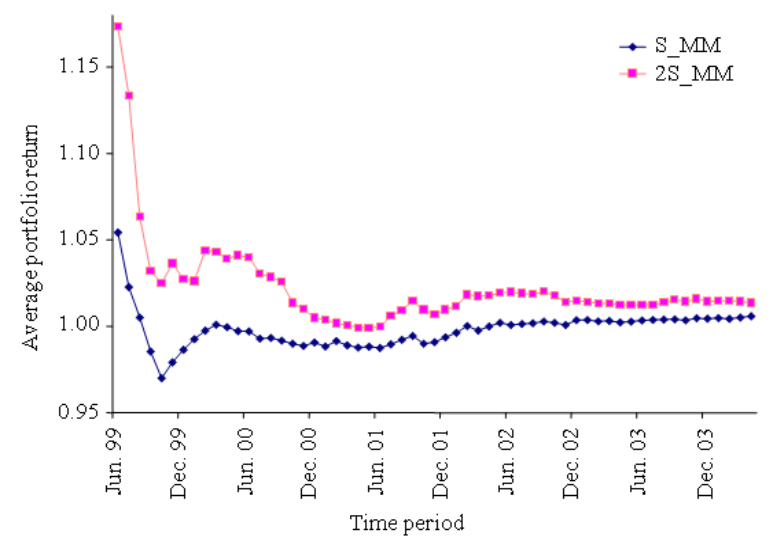

Fig. 2: Comparison of average in-sample portfolio return between S_MM and 2S_MM models

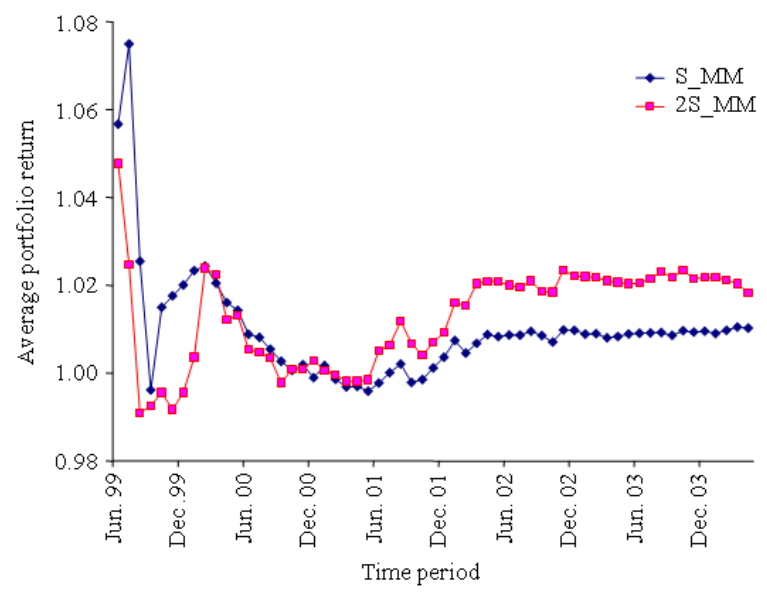

Fig. 3: Comparison of out-of-sample analysis between single stage S_MM and two stage 2S_MM models

The optimal portfolio returns of the two models exhibit the same pattern. There is a decreasing trend in the optimal returns in both models. However, in Fig. 1, it can be seen that the optimal portfolio returns from the two stage stochastic programming with recourse model, $2 S \_M M$ are higher than the optimal portfolio returns from the single stage stochastic programming model,

S_MM in all testing periods. This shows that an investor can make a better decision regarding the selection of stocks in a portfolio when he takes into consideration both making decision facing the uncertainty and the ability of making correction actions when the uncertain returns are realized compared to considers only making decision facing the uncertainty alone.
Comparison of average in-sample portfolio returns between S_MM and 2S_MM: We use average realized returns to comparison In-Sample portfolio returns between S_MM model and 2S_MM model and the results are presented in Fig. 2.

There is an increasing trend in the months from December 1999 until April 2000, then decreasing trend until June 2001. Starting from June 2001 until May 2004, both averages show an increasing trend. The average in-sample portfolio returns of $2 \mathrm{~S} \_\mathrm{MM}$ are higher than the average in-sample portfolio returns in all testing periods.

Comparison of out-of-sample portfolio returns between S_MM and 2S_MM models: In real-life environment, models comparisons is usually done by means of ex-post analysis. Several approaches can be used in order to compare models. One of the most commonly applied method is based on the representation of the ex-post returns of the selected portfolios over a given period and on their comparison against a required level of return.

The comparison of out-of-sample portfolio returns between the single stage stochastic programming model, S_MM and the two stage stochastic programming with recourse model, $2 \mathrm{~S} \_\mathrm{MM}$ is also done using the average return. The results of out-ofsample analysis are presented in Fig. 3.

Throughout the testing periods, the average returns from the two models show similar patterns. There is an increasing trend in the months from December 1999 until December 2000, then decreasing trend until June 2001. Starting from June 2001, both averages show an increasing trend. The average out-of-sample of the twostage model, 2S_MM is higher than those of single stage model, S_MM. Certainly, the models have been applied directly to the original historical data treated as future returns scenarios thus loosing the trend information. Possible application of some forecasting procedures prior to the portfolio optimization models, we consider, seems to be an interesting direction for future research. For references on scenarios generation by Carino et al. ${ }^{[3]}$.

\section{DISCUSSION}

Uncertainty is an inseparable property in financial decision making. To handle such problems, one needs to utilize probabilistic methods alongside with optimization techniques. The models were developed for risk-averse investors and the objective of the stochastic programming models was to minimize risk. The study more significant if involve the investment in 
multi period where the optimal portfolio can be evaluated monthly and annual return is calculated. The return of the future portfolio can be further improved if the future returns can be forecast more accurately.

\section{CONCLUSION}

In this study, a portfolio selection of stocks with maximum downside semi deviation measure is modeled as a single stage and a two stage stochastic programming models. Single stage model incorporates uncertainty in the model and in the two stage model the uncertainty is incorporated in the models and at the same considers rebalancing the portfolio composition at the end of investment period. The comparison of the optimal portfolio returns, the in-sample portfolio returns and the out-of-sample portfolio returns shows that the performance of the two stage model is better than that of the single stage model. Here, we use historical data as scenarios of future returns. In our future research we will generate scenarios of future asset returns using appropriate scenario generation method before applying to our developed models.

\section{ACKNOWLEDGEMENT}

The research funded by the FRGS (Fundamental Research Grant Scheme) of Ministry for Higher Education of Malaysia, Grant 203/PJJAUH/671128 University Sains Malaysia.

\section{REFERENCES}

1. Acerbi, C., 2002. Spectral measures of risk: A coherent representation of subjective risk aversion. J. Bank. Finance, 26: 1505-1518. http://ideas.repec.org/a/eee/jbfina/v26y2002i 7 p150 5-1518.html

2. Artzner, P., F. Delbaen, J.M. Eber and D. Heath, 1999. Coherent measures of risk. Math. Finance, 9: 203-228. DOI: 10.1111/1467-9965.00068

3. Beale, E.M.L., 1955. On minimizing a convex function subject to linear inequalities. J. R. Stat. Soc. Ser. B., 17: 173-184. http://www.jstor.org/pss/2983952

4. Carino, D.R., D.H. Myers and W.T. Ziemba, 1998. Concepts, technical issues and use of the russelyasuda kasai financial planning model. Operat. Res., 46: 450-463. http://portal.acm.org/citation.cfm?id=768130

5. Chang, K.H., H.J. Chen and C.Y. Liu, 2002. A stochastic programming model for portfolio selection. J. Chinese Inst. Ind. Eng., 19: 31-41. http://www.jciie.ciie.org.tw:8080/archive/abstract/ English/v19/19_3/19_3_6_en.htm
6. Consiglo, A. and S.A. Zenios, 2001. Integrated simulation and optimization models for tracking international fixed income indices. Math. Programm., 89: 311-339. DOI: 10.1007/PL00011401

7. Crane, D.B., 1971. A stochastic programming model for commercial bank bond portfolio management. J. Financ. Quant. Anal., 6: 955-976. http://www.jstor.org/stable/2329914

8. Dantzig, G.B., 1955. Linear programming under uncertainty. Manage. Sci., 1: 197-206. http://www.stanford.edu/class/msande348/papers/ Dantzig_original_sp_paper.pdf

9. Hiller, R.S. and Eckstein, J., 1993. Stochastic dedication: Designing fixed income portfolios using massively parallel Benders decomposition. Manage. $\quad$ Sci., $\quad 39$ : 1422-1438. http://cat.inist.fr/?aModele $=$ afficheN\&cpsidt $=3914$ 482

10. Konno, H. and H. Yamazaki, 1991. Mean-absolute deviation portfolio optimization model and its application to Tokyo stock market. Manage. Sci., 7: 519-531. http://portal.acm.org/citation.cfm?id=107582

11. Markowitz, H.M., 1952. Portfolio selection. J. Finance, 8: 77-91.

12. Markowitz, H.M., 1959. Portfolio Selection: Efficient Diversification of Investment. 2nd Edn., Basil Blackwell, John Wiley and Sons, New York, ISBN 978-1557861085, pp: 341.

13. Sortino, F.A. and H.J. Forsey, 1996. On the use and misuse of downside risk. J. Portf. Manage., 22: $35-42$.

14. Young, M.R., 1998. A minimax portfolio selection rule with linear programming solution. Manage. Sci., 44: 673-683. http://cat.inist.fr/?aModele $=$ afficheN\&cpsidt $=1637$ 432

15. Worzel, K.J., C. Vassiadou-Zeniou and S.A. Zenios, 1994. Integrated simulation and optimization models for tracking fixed-income securities. Operat. Res., 42: 223-233. http://cat.inist.fr/?aModele $=$ afficheN\&cpsidt $=4257$ 210

16. Zenios, S.A., 1995. Asset/liability management under uncertainty for fixed income securities. Ann. Operat. Res., 59: 77-97. DOI: 10.1007/BF02031744

17. Zenios, S.A., M.R. Holmer, R. McKendall and C. Vassiadou-Zeniou, 1998. Dynamic models for fixedincome portfolio management under uncertainty. J. Econ. Dyn. Control, 22: 1517-1541. DOI: $10.1016 / \mathrm{S} 0165-1889(97) 00115-2$ 